\title{
Use of community radio to communicate agricultural information to Zimbabwe's peasant farmers
}

\author{
Sailas Nyareza and Archie L. Dick \\ Department of Information Science, University of Pretoria, Pretoria, \\ Republic of South Africa
}

\begin{abstract}
Purpose - The objective of this paper is to investigate the benefits and limitations of using radio to communicate agricultural information to peasant farmers, and how radio can be successfully incorporated into agricultural extension service programmes.

Design/methodology/approach - Quantitative and qualitative research techniques were used and applied to gather, analyse and interpret data. Twenty-five semi-structured interviews were conducted with peasant farmers, and four in-depth interviews were conducted with key informants involved in agricultural extension and radio services.

Findings - It was found that although peasant farmers are well-aware of extension service programmes, they do not satisfy their agricultural information needs. This is because there are not enough extension workers, they do not have the means of transport to reach all households, they lack the communication skills to effectively interact with the peasant farmers, and they lack the motivation to carry out their work. A community radio service was the most preferred medium of communication for rural peasant farmers. The farming programmes are relevant to their own agricultural activities, their own language and accents are used, and they can contribute to the programme content.

Originality/Value- The study proposes a strategic model that could be used to communicate agricultural information effectively to peasant farmers. The proposed model elaborates how the community radio service should be set-up, the important elements to be included, and how the community radio service can be incorporated effectively into extension service programmes.
\end{abstract}

Keywords - Agricultural extension services, Development communication, Peasant farmer, Radio, Zimbabwe, Agriculture, Social interaction, Communication

Paper Type - Research paper 


\section{Introduction}

Agriculture plays an important role in the development of the Zimbabwean economy through its impact on the overall economic growth, households' income generation, and food security. Approximately $80 \%$ of the population is dependent on agriculture for their livelihood. The Government of National Unity's (GNU) roadmap document, namely the Short Term Emergency Recovery Programme (STERP) explained that the government will capacitate farmers by improving access to inputs and enhancing their skills through training, extension services, and effective communication of agricultural information (FANRPAN, 2009).

Information is important for farmers to maintain livelihoods and to gain a competitive edge in a rapidly changing economic and production environment where traditional farming methods might be ineffective to meet new demands (Morton \& Matthewman, 1996). Unfortunately, most African countries have not devoted enough attention to provide their citizens with access to information, especially in rural areas where $70-80 \%$ of the African population lives (Youdeowei, Diallo \& Spiff, 1996).

Agricultural extension represents a mechanism by which information about new technologies, better farming practices, and better management can be transmitted to farmers. Reisenberg \& Gor (1989) stated that the extension services are experiencing a declining impact and more emphasis is being placed on the use of mass media for agricultural information transfer. Zijp (2003) observed that face-to-face communication between extension agents and farmers, while crucial, cannot fulfill all of the farmers' information needs. Extension agents are too few in number and, particularly in emergency situations like those related to weather or a pest infestation, time is too short. As a result, radio has been recognized as a highly cost-effective technology to convey information, training, and technology in rural areas.

Elsewhere in the world there has been a notable increase in the use of radio since the 1980s. The successes of radio have been observed in Botswana for civics education, in India for rural development, in Nigeria's agricultural sector, in the Benin Republic to educate rural peasant farmers (Nwaerondu \& Thompson, 1987), and in Malawi to communicate agricultural and rural development information (Manyozo, 2005). In Zimbabwe, the Federation of African Media Women (FAMWEZ) established radio listening clubs for women in the Mhondoro District in a project called "Development Through Radio". The project managed to yield tangible benefits in the forms of borehole drilling, sanitation resources for women, and income generating projects (George, 1993).

The aim of this study was to investigate the benefits and limitations of radio to communicate agricultural information to peasant farmers, and how radio can be 
incorporated successfully into an agricultural extension service programme in the Buhera South Constituency of Zimbabwe. The results of this study will provide new information about the potential of radio and how it can be successfully incorporated into existing extension service programmes to provide effective agricultural communication to rural dwellers. A strategic model was developed and is recommended for adoption in other rural communities.

\section{Agricultural extension service programmes in Zimbabwe}

Hunyani-Mlambo (2002) identified the following as major successes of the extension service programmes in Zimbabwe's rural areas:

- An increased production of crops such as maize and cotton by communal farmers in the last 20 years;

- The promotion of national development through participation in, and the initiation of, rural development projects;

- Restored confidence in professional and technical extension services; and

- People's development through rural development projects that are planned, initiated, and facilitated by the Department Of Agricultural Research, Technical and Extension Services (AGRITEX).

He also pointed out the opportunities for Zimbabwe's agricultural extension service programmes. They are plentiful in terms of collaboration among the actors in the extension system. There is room to involve local communities in most intervention issues, and there are excellent opportunities for strategic government agency/NonGovernmental Organisations (NGO) alliances with local private companies in various sectors, despite the threat of donor fatigue and withdrawal.

Hunyani-Mlambo highlighted the major weakness of the agricultural extension service programmes as AGRITEX's failure to identify farmer-developed technologies that work, and that can be adapted for farmers in other wards, districts or provinces. This has been made worse by an inadequate operating budget and the lack of transport, which have severely limited extension agents' contact with farmers.

During the Southern African Development Community Multi-country Agricultural Productivity Programme (SADC MAPP, 2007) workshop in Harare from 10-11 September 2007, the stakeholders observed the following weaknesses in Zimbabwe's extension services programme:

- Inadequate skilled human and material resources to produce farmers' literature;

- Basic in-service obligatory training of extension staff has stopped due to limited resources;

- Extension worker - farmer ratio is low; 
- Low motivation of extension workers and high staff turnover;

- Poor linkages between farmers, extension workers and researchers;

- Lack of recognition of farmers' innovative and indigenous knowledge;

- Farmer training is 'abstract' as opposed to 'hands-on'; and

- Untargeted farmer service provision.

\section{The use of radio as a communication medium}

Radio is used extensively as a communication medium in developing countries to support educational programmes in teaching, health, literacy training, nutrition education, and the promotion of changes in farming practices to improve agricultural production (Nwaerondu \& Thompson, 1987). While other communication media like television remain in the hands of a small percentage of people, low-cost transistor radios run on batteries are now affordable for the poorer sections of the population. Furthermore, radio as a communication medium does not require literacy. The increasing shift to local radio program production and broadcasting is also removing barriers of language and dialect. As a result, radio has become a valuable medium of communication and dissemination of information, as well as for training and education for broad segments of rural communities (Zijp, 2003).

Many experts identify radio as the most appropriate medium for rural emancipation programmes (Okwu, Kuku \& Aba, 2007). The advantages are that:

- It overcomes distance, and thus has immediate effect;

- It is the only medium of mass communication that the rural population is very familiar with because a radio set is cheap to obtain and is widely owned in the rural areas. This is made possible by the advent of the battery-operated transistorized sets and the invention of wind-up radio (Kuponiyi, 2000);

- Radio's power contributes to mass education because it is easier to attend to than print, and it is more accessible. Listening is easier than reading, and if people of low cultural level are interested in serious subjects, then radio is a more effective way of communication than print (Lazarsfeld,1940); and

- The use of radio to disseminate agricultural information is relatively when compared with other media. In Malawi one project evaluation found that radio trained farmers in new agricultural techniques cost 3,000 times less per hour than face-to-face extension services (Zijp, 2003).

The disadvantages of radio are:

- Radio ownership: because not all rural dwellers own a radio set, and the batteries to power the radio are expensive for rural peasants (Makunike-Sibanda, 2001);

- Transmission problems, which hamper the effective use of radio in community development. However, the invention of the wind-up radio by Trevor Baylis and 
the subsequent manufacture of the Freeplay by the Baygen Company of South Africa is one solution to the problem of diffusing radio to remote communities (Hartley, 2000); and

- Potential abuse: because radio's ubiquity and ease of access means that it is available for the free expression of ideas, and can be used to build communities of hate. It can also be abused by politicians and other leaders in the society (Hartley, 2000).

\section{Models of community radio services}

Community radio stations are expected to pursue social development agendas, to respond to the community's expressed needs and priorities, and to be accountable to their stakeholder communities through an ongoing interactive and consultative process. They give listeners a sense of community and identity and create action spaces for people to have both direct and indirect links with community power structures, as well as access to resources (Megwa, 2007). The Radio Farm Forum (RFF) Model and the Development Through Radio (DTR) Model are two models of community radio services that are relevant to this study.

The RFF was started in Canada in 1941 as a radio discussion forum and served as a model that was adopted subsequently in a number of developing countries (Nwaerondu \& Thompson, 1990). The Farm Forum model encouraged the members of isolated farming communities who did not have access or had little access to radio to gather at one farmer's house each week to listen to the programme. The programmes were on subjects such as agriculture, health, and literacy. After the broadcast they would discuss the programme content and any other related farming issues with their neighbours (George, 1993). Listeners were encouraged to write to the programme with questions, problems, and ideas emanating from the broadcast, and their contributions formed part of the subsequent programmes.

The RFF model died out with the demise of donor funding (George, 1993). Another possible reason for the demise of the RFF experiments was the lack of research and evaluation to demonstrate that they actually made a positive difference in the lives of the group members or their communities. Those who advised on the replication of the RFF model advocated the establishment of evaluation strategies or a model that recognizes the importance of evaluation to determine the impact and ensure sustainability.

The DTR model evolved from the RFF concept. This model was first implemented in 1985 in Zimbabwe by FAMWEZ in collaboration with UNESCO, the Friedrich Ebert Foundation, and Zimbabwe Broadcasting Corporation (ZBC) Radio 4. The project mainly targeted women in the rural areas. Radio listening clubs with a membership ranging from 
10 to 20 women would gather together once a week to listen to a DTR radio broadcast in their vernacular language and then discuss and comment on the broadcast. Members would raise issues from their discussions to be addressed in the next DTR programmes. By facilitating the audience's participation in the message selection, programme design and theory, the DTR model encourages cultural relevance for the listeners and a keen interest in the message to be broadcast.

This study investigates the potential benefits and limitations of using radio to communicate agricultural information to peasant farmers and proposed an adapted model.

\section{Methodology}

This study was carried out in Ward 16 of the Buhera South Constituency which is located in the Buhera District, in the Manicaland Province of Zimbabwe. The constituency is made up of sixteen rural wards, and is a purely communal area where most of the peasant farmers are found. The ward has a population of 6085 people. It has four primary schools, three secondary schools, two health facilities and five small business centres.

It was decided to conduct the research at all five business centres in Ward 16 of the Buhera South Constituency. This selection was made on the basis of purposive and convenience sampling. It was decided to do the study at business centres because it is at those places that the farmers go to sell their produce like tomatoes, groundnuts and other food products. It is also the venue for community meetings. Another reason for conducting the research at the business centres is the fact that they are used as focal points by extension service programmes, AGRITEX, and by other NGOs operating in the region.

The targeted groups for this study were the peasant farmers in Ward 16 of the Buhera South Constituency. The residents of this communal area depend on agriculture for their day-to-day living. The major crops grown in the area are maize, millet, groundnuts, and rapoko. The peasant farmers also grow vegetables and tomatoes in their gardens, which are all over the banks of the Zvipanga and Nyazvidzi Rivers. In good seasons, they sell their surplus to the Grain Marketing Board, and they also sell their vegetables at the business centres. They also rear cows, goats, sheep and donkeys. The cows and donkeys are mostly used for draught power when ploughing in the fields.

The sampling method used in the study can be best described as a combination of nonprobability methods, namely, purposive, convenience, and volunteer sampling. Peasant farmers selling their produce at the business centres were randomly approached according to the guidelines of purposive sampling which involves the random selection of a small sample with the emphasis on information-rich samples instead of generalizing to 
a broader population. Five peasant farmers as participants were chosen at each of the five business centres.

The sampling took place as follows: At the agricultural produce markets, people arrive early and set up their market stalls. The researcher randomly approached these people as they were setting up or manning their market stalls. After the peasants farmers were invited to take part in the study and were shortly briefed on the purpose, they could decide whether they wanted to take part or not. The farmers then either agreed to take part, or refused. In this way, the researcher could ensure that each business centre still yielded five interviews, and a sum total of twenty-five interviews. Peasant farmers at the business centres willingly consenting to participate were viewed as volunteering to take part in the study.

Key informants from four organizations working in the area were also interviewed. The informants were from the following organizations:

- Department of Agricultural Research, Technical and Extension Services (AGRITEX);

- Zimbabwe Broadcasting Holdings (ZBH), Radio 2;

- Meteorological Services Department; and

- Zimbabwe Broadcasting Authority (ZBA).

The organizations were chosen based on the work they are doing in the Buhera South Constituency, that is, provision of extension service programmes, radio services and weather information. After a telephone conversation to brief the organizations on the research project, they agreed to provide a key person to be interviewed.

\section{Findings and Discussion}

Profile of respondents

Seventy-two percent $(72 \%)$ of the respondents were found to be female and $28 \%$ were male. This may imply that the Ward has more females than males, or because it is very common for the males to go to urban areas to look for jobs whereas the females remain in the village and constitute the majority of the peasant farmers. Those who had reached Form 2 (nine years of schooling) can be considered functionally literate. They were the largest portion (40\%) in this group. Most of them, however, indicated that although they did their Form 2 some decades ago they are no longer functionally literate because they have been in the rural areas. This suggests that the literacy levels seem to be declining with time, age, and lack of practice. Fourteen (56\%) of the respondents indicated that they could read and write, although some respondents were too embarrassed to say that they cannot read and write. 
Figure 1. Educational levels of respondents

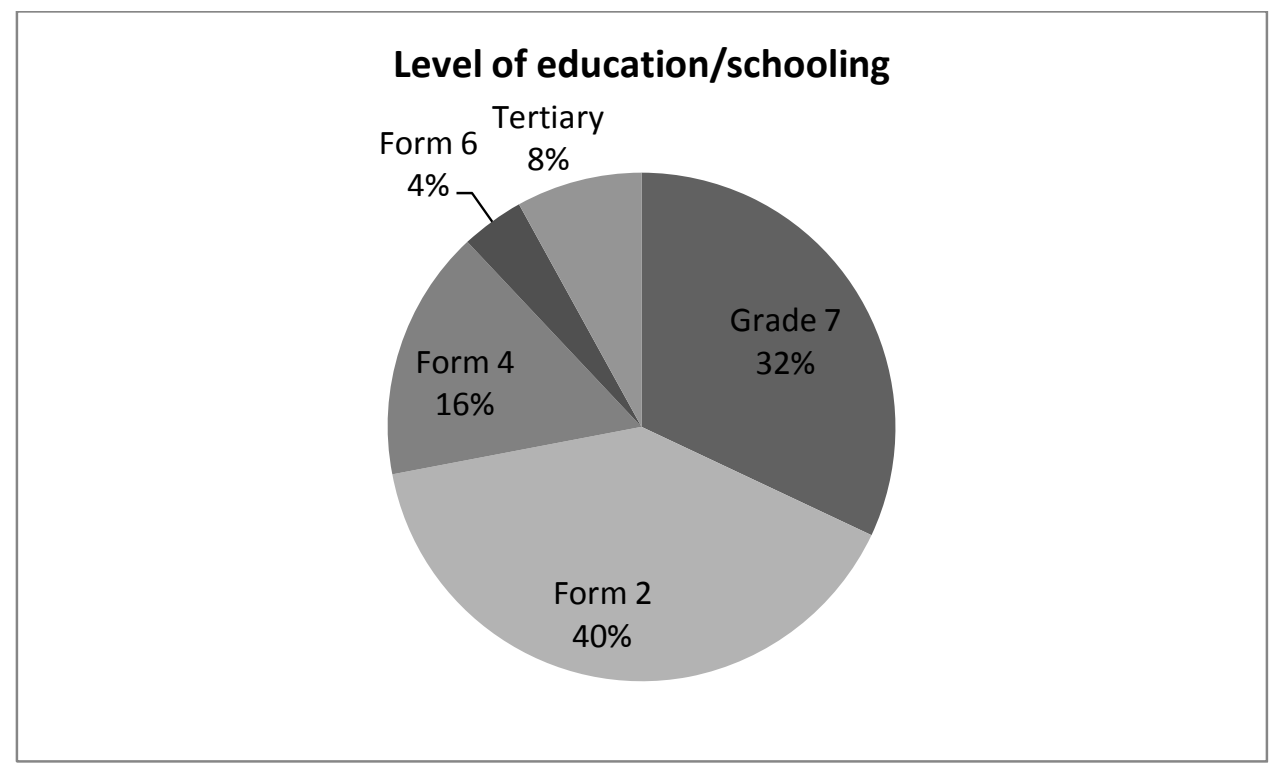

The major crops in the ward are maize, sorghum, millet and groundnuts and the animals which they rear are cows, goats and sheep. None of the respondents sold any surplus to the Grain Marketing Board (GMB) in the 2008/09 farming season. Twenty (80\%) of the respondents indicated that they get their income from farming, three (12\%) from support from extended family, and the other two (8\%) said they do not have any income. Thus, the majority rely on farming. This underscores the importance of farming to the rural community, and hence the pivotal importance of effectively communicating agricultural information as a way of empowering them.

\section{Training}

Fourteen $(56 \%)$ of the respondents have never had any kind of training on farming. The other $44 \%$ received some kind of informal training from the extension officers through field days, agricultural shows, and master-farmer training programmes. The fact that the majority of peasant farmers have never had any kind of training could be because the extension officers are not able to do their outreach to all households in the community. This matter was probed further in the interview with the Senior Agricultural Extension Officer for the Buhera South Constituency. It was revealed that the individual contact extension method has not been effective because the ward has only 4 extension workers and each is expected to cover about 500 households, and also they do not have transport to cover all households. 


\section{Sources of information}

Their main sources of agricultural information were indicated as follows: extension agents (54\%); radio (46\%); and information leaflets/brochures (37\%). Extension services are well known in the district as the major source of agricultural information. Twenty of the respondents $(80 \%)$ said they are aware of the extension workers in their ward but they feel that they are not doing enough to communicate agricultural information. They suspected that the extension agents are not doing well due to lack of transport to cover all households in their respective wards. Radio was ranked second, and this means that if extension agents who are well-known in the district use radio in their work, then a very effective agricultural communication service programme for the rural peasants may be produced.

AGRITEX leaflets are not very popular. Sixty-four percent (64\%) of the peasant farmers indicated that they do not understand them. This could be because most of the farmers are in the 45-55, and 55 and older age groups and are not able to read and understand these pamphlets, and also because their literacy levels are declining with age. They indicated that they cannot understand the message because of the use of technical terms and scientific names in leaflets, such as, "SC507" which is a maize seed hybrid. There is also no chance for further explanation or asking questions. It is a case of either you understand or you do not.

\section{Use of radio}

Eleven $(44 \%)$ of the respondents indicated that they own a radio at their homes. Fourteen (56\%) said they do not own a radio, of which eight said that they listen to radio at the business centre or at their neighbour's home. The major reason why the other six do not listen to radio is because they believe it is used for political purposes and they are weary of propaganda. Some said they are not interested and they do not have access to the radio. The data shows that radio ownership and the batteries to run the radio are the major impediments to the use of radio to communicate agricultural information to rural dwellers. It is interesting to note though that those who do not own radios do have an interest and that they make a special effort to listen to their favourite programmes.

Twenty-two (88\%) of the respondents said they listen to Radio Zimbabwe. The main reasons why they listen to Radio Zimbabwe are that: its programmes are presented in their local language; they present more farming programmes; and they receive useful information such as weather, death notices, entertainment dramas, and their favourite local music. This data was confirmed in the interview with the representative from Radio Zimbabwe who indicated that the radio has the widest coverage, and its target audience is the rural people. Its languages are Shona and Ndebele, the two main local languages. 
Table 1. Favourite radio stations

\begin{tabular}{|l|l|}
\hline Radio station & number \\
\hline Radio 1 & 0 \\
\hline Radio Zimbabwe & 22 \\
\hline 3fm & 1 \\
\hline Radio 4 & 2 \\
\hline
\end{tabular}

The majority of the respondents indicated that they like radio, but they also pointed out the reasons why they dislike radio at times. They gave the following as their answers:

What do you like about radio?

- Those who are illiterate can understand the programmes;

- Farming programmes;

- Variety of programmes- farming, economy, culture, education and health;

- Use of local language;

- Entertainment programmes like local dramas and local music; and

- Weather information.

What do you dislike about radio?

- Its use is dependent on the availability of power, and batteries are now expensive;

- Propaganda from politicians spoil all the programmes;

- Poorly planned programmes;

- It is expensive to buy a radio set;

- We do not have any influence on the programming; and

- Some advertisements are annoying.

The answers suggest that although rural dwellers may perceive the value and effectiveness of a communication medium, they are also very skeptical about initiatives to empower them. They tend to approach every development initiative with caution, and are very skeptical of political maneuvers, and particularly about protecting their cultural values. For these reasons they do not need the political propaganda and commercial advertisements. The involvement of the rural communities in establishing the community radio station will go a long way to allay such fears, as they will feel that they are partners in ownership of the station. The reasons also suggest that commercial radio stations are not popular with rural dwellers especially because of the repetitive commercial advertisements, and most of the things advertised are not available in rural areas 
These concerns were confirmed in the open-ended interview with the Head of Radio Programmes at Radio Zimbabwe, who indicated that since the station is a national radio, they sometimes change their programming schedules to cover important national events, like burials of national heroes, presidential speeches, and sometimes towards elections they cancel some programmes to cover events such as political debates and advertisements.

\section{Radio and the communication of agricultural information}

Almost all the respondents agreed that radio is indeed very useful in communicating agricultural information, and the following reasons were highlighted to support their opinion:

- Timely dissemination of information;

- There is much more elaboration on the issues affecting peasant farmers;

- No discrimination; and

- Radio cannot be affected by bad weather.

The reasons given by the farmers suggest that the extension agents are not doing a good job in elaborating the issues affecting the farmers. The extension agents may also be showing some discrimination and favouritism in the delivery of extension services, and bad weather prevents them from reaching all households. This was probed further in the interview with the Senior Agricultural Extension Officer. He highlighted transport problems to move from one place to another and extension officers are not enough. When further pressed on the weaknesses of their extension staff to verify the reasons given by peasant farmers in semi-structured interview, he highlighted that some of them lack good communication skills and some end up liking and disliking certain households in their respective wards.

Two $(8 \%)$ interviewees indicated that radio is not useful for communicating agricultural information because not all peasant farmers own radios, and because transmission problems affect the dissemination of the information, and information may be politically motivated. A community radio station which is not driven purely by commercial or political motivations but which offers a platform for community participation and decision-making may be the solution to these problems. The idea of using radio to complement extension services was fully supported, with respondents indicating that the use of radio will enable extension workers to reach more households, and programmes will be aired at the most relevant time. The meteorological office, the veterinary services, and livestock auction dealers can all be integrated into the radio programmes resulting in an effective agricultural information communication service. 
The Agrometeorologist at the Zimbabwe Meteorological Services (ZMS) also indicated that they are planning to have community-based radio stations for the dissemination of agro-met information. He indicated that they have applied for assistance from the African Centre of Meteorological Application for Development (ACMAD) to get the low-cost transmitters and the radio sets. The government of Zimbabwe has also expressed willingness to help in the project. He explained that ones the transmitters are secured local shops or schools can house the station and they intend to use local people as presenters.

\section{Setting up a community radio station}

Seventy-six percent (19) of the respondents said they liked the idea of a community radio station because it will provide agricultural information that is most relevant to the district using their own local language. They maintained that the current programmes they listen to on Radio Zimbabwe rarely cover the Buhera South Constituency. A community radio station will be a platform for the peasant farmers to share information, and their area specific information needs will be addressed. The other six (24\%) said they are worried that politicians might take advantage of community radio stations, and that radio programmes do not have the important element of demonstrations, which they think are really crucial.

\section{Sharing knowledge and experiences of agricultural activities to radio programmes}

The majority of the respondents indicated that they are willing to share their knowledge and experiences of agricultural activities on radio programmes, but they were quick to point out that they would do so only if it is on a community radio. Many are afraid to speak on national radio as they fear political victimization. Their fears are possibly rooted in the political violence that bedeviled the country in the 2008 general elections when people were victimized.

\section{Financial sustainability}

Some of the respondents indicated that although they support the idea of setting up a community radio station in Ward 16, they are not sure about the financial sustainability of the station. Who will fund the initial set-up, equipment costs and manpower to run the station? How is the day-to-day running of the station going to be financed? They indicated that they are willing to mould bricks to build the housing for the station, and share their experiences in farming on the station, but they cannot afford to contribute financially. The Senior Agricultural Extension Officer for Buhera indicated that since the radio will now be one of the tools used by the extension services agents they could channel part of the extension budget to the community radio station. They would also stop employing more extension agents and channel the resources to the radio listening clubs to strengthen their field days and group meetings. 


\section{Community Radio for Development model}

On the basis of the findings a Community Radio for Development model that is suited to agricultural information needs of peasant farmers is proposed. The Radio Farm Forum and Development Through Radio models are valuable but ultimately unsuited to the needs of a community like Buhera South. A model to be called the Community Radio for Development model (CRD), adapted from the above two models and that draws on the empirical data of this study is therefore proposed. The CRD model will provide a service with a strong focus on agricultural information for peasant farmers, and will include a few items on other issues such as health and environmental issues. It will then expand to other areas in time, but its primary focus will be agricultural information.

Figure 2. provides the graphic representation of the proposed model and all its major components.

The following major components which makes the CRD model are explained further and how they will connect to each other to deliver an effective information service to the peasant farmers.

Initial setting up of a community radio service

A community radio service has to be set-up and should be based in Ward 16 of the Buhera South Constituency. The station could use the low-cost transmitters and the radio sets distributed by the African Centre of Meteorological Application for Development (ACMAD). The setting up of the community radio station would be similar to the way in which Dzimwe Community Radio was successfully set-up in Malawi in 1998 (Manyozo, 2003). This entail having community members involved in the initial set-up of the station, who can be elected to become members of the station's management committee. To kick-start the process the issue of the community radio service can be included on the agenda of the community meetings. Members may consist of a chairperson, vicechairperson, monitor, secretary, treasurer and regular members, and they will operate on a set of guidelines, roles and principles determined by the community itself. The management committee will report to the board of trustees, comprising senior traditional, social, and local leaders. The management committee will appoint a Station Manager, 
Figure 2: Community Radio for Development model for communicating agricultural information

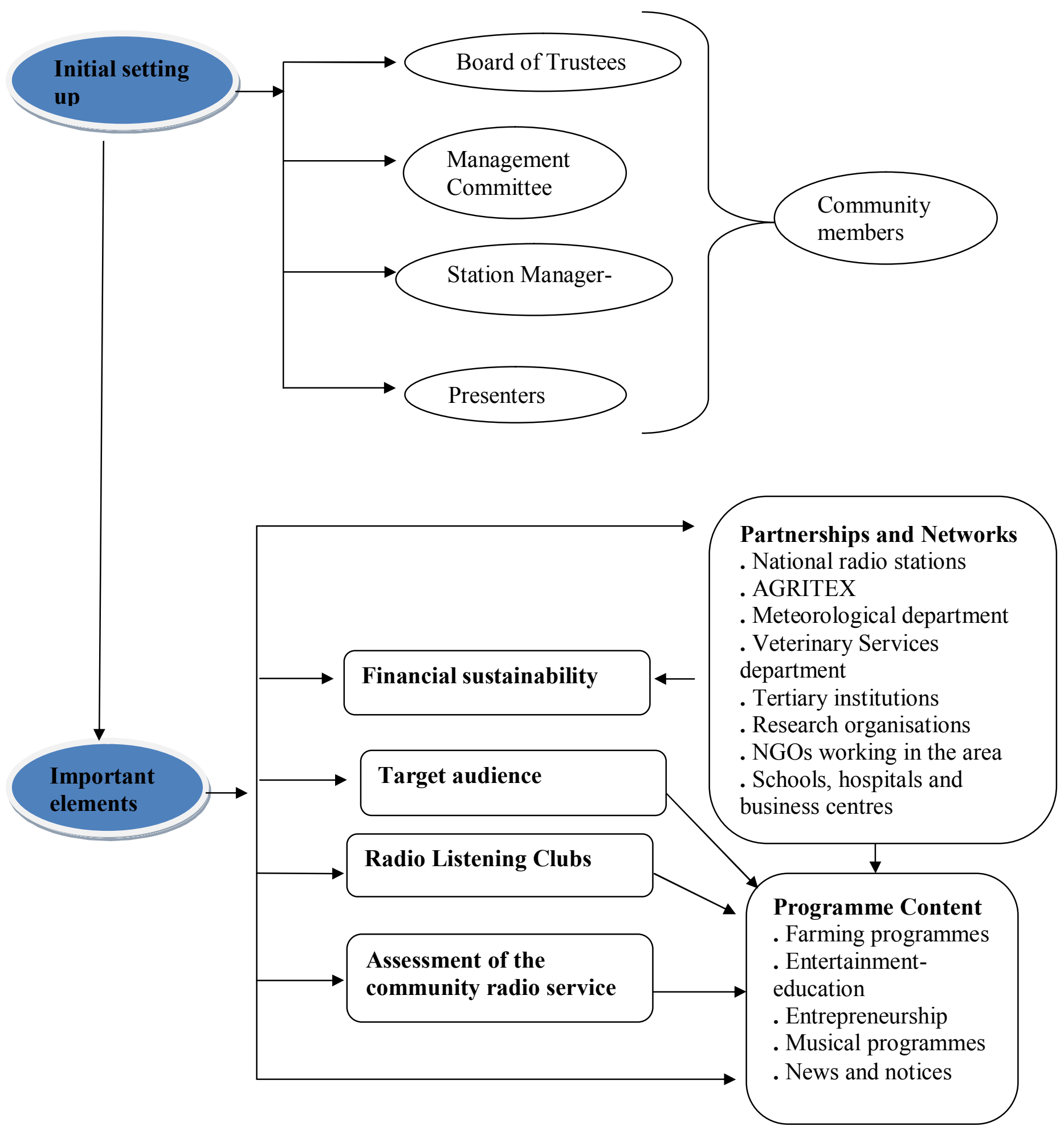


who will maintain a duty roster and make sure that the station has the daily programme.

\section{Staffing}

The station has to maintain a partnership with existing national and commercial radio stations under the Zimbabwe Broadcasting Holdings, primarily Radio Zimbabwe which was indicated as the most popular station by the respondents. The station can set up exchange programmes with those radio stations to get their volunteers trained on how to present the programmes and also on the servicing of equipment. Extension officers from AGRITEX, Veterinary officers from the Department of Livestock, and local peasant farmers trained under the master farmer training programme of AGRITEX could all be trained as presenters. These would be local people who speak in the language and accent of the community. Agricultural extension service programmes will then be prepared by those trained community radio agricultural extension officers.

\section{Partnership and networks}

The community radio station has to partner with the local institutions like schools, hospitals, business centres, non-governmental organizations working in the area, the AGRITEX Buhera Office, Veterinary Services Department, the Grain Marketing Board (GMB) and tertiary institutions. Local members of the community could assist in providing building materials for the station. The AGRITEX unit indicated in the interviews that they could use a portion of their budget to fund the community radio station since it will help them as an extension tool to reach out to peasant farmers. Local schools and business centres can also house the radio station. They already have the goodwill since they currently house extension agents. Non-governmental organizations, governments departments and local clinics are all good partners who will use and contribute to the long-term sustainability of the station.

Partnerships and networks will also help to access agricultural research material to support the range of topics requested by peasant farmers. This also improves the linkages between agricultural research and rural radio, and ultimately the rural dwellers will benefit. Partnerships with other national, community and commercial radio stations will be helpful in skills transfer. Other organizations like the Meteorological Services Department and ACMAD which is distributing low-cost transmitters will be important partners to network and with which to collaborate.

\section{Financial sustainability}

Local non-governmental organizations, government departments like the AGRITEX, Meteorological, and Health and Environmental departments could be approached to channel funds to the community radio station. Interviews with the AGRITEX and Meteorological Services revealed that they are willing to contribute to the start-up capital 
and sourcing of the equipment like transmitters and the radios. The local councillor for Ward 16 will also be approached to help in fundraising for the community radio station. This may entail negotiating with the Buhera Rural District Council to contribute to this project.

\section{Programme content}

The programmes have to be in line with the Broadcasting Services Act (2001) of Zimbabwe which defines a community radio as a "free-to-air broadcasting service not operated for profit or as part of a profit-making enterprise which provides for community purposes, does not broadcast programmes or advertisements on behalf of any political party and is capable of being received by commonly available equipment". Unlike the Farm Forum Radio model, the programmes will not only be about agriculture or on women's issues as in the Development Through Radio model but will also deal with health and environmental issues, and include entertainment programmes and informative segments. Fifty percent $(50 \%)$ of the programmes could focus on farming and related activities.

The programmes need to have a strong emphasis on entrepreneurship so that rural dwellers can be taught how to start their own agricultural related income-generating projects. Such programmes could include areas like bee-keeping and mushroom harvesting. Experts in these areas could be invited to the radio station to discuss in detail the matters, and in this way empower farmers to start such projects. Peasant farmers will be empowered to participate in commercial activities, giving rise to rural-based economic development through proper exploitation of the farmers' entrepreneurial skills.

\section{Target audience}

The target audience of the community radio for development is rural dwellers, both male and female, which mainly comprise the peasant farmers. All the programmes will be in the local language, Shona. The radio station could also incorporate programmes for the youth and women. The youth who are the peasant farmers of tomorrow need to be encouraged to practice farming since it is the major economic activity in the District.

\section{Radio Listening Clubs}

Radio listening clubs will be established mainly for the peasant farmers so that they can gather and listen to a farming programme together as a way of facilitating development discourse within their own community. A local extension worker can also join them during such discussions. Their discussions can be recorded and then broadcasted on the community radio. In this way, different discussions from various listening clubs in the Ward will be beneficial to the peasant farmers. A farming programme can concentrate on a specific village for that day, and on the next day it will deal with another village. The 
discussions are broadcasted, and they will stimulate discussions in other villages. Extension workers will then be called regularly to the farming programmes to address specific issues emanating from the discussions. Specific questions can also be directed to the relevant department, for example questions relating to environmental degradation, livestock dipping, and water conservation.

\section{Entertainment-Education}

An important element to be incorporated in this model is that of entertainment-education. Singhal (1999) refers to entertainment-education as the process of purposively designing and implementing a media message both to entertain and educate in order to increase audience members' knowledge about an educational issue, create favourable attitudes, and change behaviour. Most of the peasant farmers indicated that they like radio because of the entertainment programmes such as dramas and local music. The dramas could be used to reinforce messages on crop rotation, the need to conserve the environment, and also music which encourages young people to take up farming instead of flocking to urban areas to look for work. Framing the messages in a popular, entertaining format helps create an environment where people can carry on conversations about topics discussed in the latest episode of the favourite drama. The dramas to be included could be on people discussing or sharing information on bush-burning, long-term soil fertility, and the growing of cash crops.

\section{Assessment of the community radio service's agricultural communication functions}

An evaluation of the community radio service will be necessary after an agreed period of time to determine if the programmes and the way they are delivered are effective. The evaluation will seek to discover if peasant farmers understand the programmes well, which programmes are most popular, and what else the farmers would want to see included in the station's programming. Okwu (2007:15) highlighted that an evaluation of a radio service for a community would look at:

- Identifying agricultural programmes being aired by the community radio station;

- Finding out the levels of patronage of the programmes;

- Ascertaining the convenience of the time of presentation to the target audience;

- Determining the relevance of the programmes to the information needs of the peasant farmers; and

- Ascertaining agricultural knowledge gained by the farmers.

A reliable participatory evaluation methodology will be used (Kellog Foundation, 1998:11). This will be primarily concerned with the following: 
- Creating a more egalitarian process where the evaluator's perspective is given no more priority than that of other stakeholders, including programme participants and all other stakeholders in the programme;

- Making the evaluation process and its results relevant and useful to stakeholders for future actions; and

- Fostering the collaboration of project staff (including local partners) and other stakeholders in taking stock of the project strategies, implementation procedures, and progress towards achieving the results set. It emphasizes looking at the processes from the perspective of all the different actors, namely programme management staff, country partners, external partners, and the donors.

\section{Conclusion}

The community radio will be used as an extension tool which can take technical information from the wider agricultural research community, including the local universities, research institutes, rural development centres and non-governmental organizations and translate it both literally and figuratively into the local language with the most appropriate accent for the peasant farmers. This model underlines the importance of moving away from the traditional way of delivering extension messages to farmers to a more proactive and participatory based way of understanding the peasant farmers, their priorities and specific needs. The community radio will also be used as a conduit to transfer technology and research results from research institutions to the peasant farmers. The proposed Community Radio for Development model would be best suited to the needs of Ward 16 of the Buhera South Constituency, but could be extended to other wards, districts and provinces in the country eventually. The reasons are that the CRD model draws on well-established models, as well as actual data for that area.

\section{References}

Food, Agriculture and Natural Resources Policy Analysis Network (FANRPAN). 2009. Short Term Economic Recovery Programme (STERP): getting Zimbabwe moving again. Available at: http://www.fanrpan.org/documents/d00685/ Zimbabwe_STERP_March2009.pdf (accessed 28 August 2009).

George, N. A. (1993), "Using Radio for Community Mobilisation: Experiences in Zimbabwe and Kenya", Africa Media Review, Vol. 7 No.2, pp. 52-68. 
Hartley, J. (2000), "Radiocracy: Sound and citizenship", International Journal of Cultural Studies. Vol. 3 No. 153, pp. 156-157.

Hunyani-Mlambo, B.T. (2002), "Strengthening the Pluralistic Agricultural Extension System: A Zimbabwean Case Study", Food and Agricultural Organisation $(F A O)$, available at: http://www.fao.org/DOCREP/005/AC913E/ac913e00.htm (accessed 12 July 2009).

Kellog, W.K. Foundation. (1998), "Evaluation Handbook: Philosophy and Expectations", available at: www.wkkf.org/ /media/62EF77BD5792454B807085B1AD044FE7. ashx (accessed 18 August 2009).

Kuponiyi, F.A. (2000), "Mass Media in Agricultural Development: The use of Radio by Farmers of Akinyele Local Government Area of Oyo State, Nigeria", Journal of Nigerian Agricultural Development Studies. Vol. 1 No. 1, pp. 26-32.

Lazarsfeld, P.F. (1940), Radio and the printed page: An introduction to the study of radio and its role in the communication of ideas. New York: Duell, Sloan and Pearce.

Makunike-Sibanda, J. (2001), “Improving Access To Rural Radio 'By Hard-To-Reach' Women Audiences", paper presented at FAO International Workshop on Farm Radio Broadcasting. Information \& Communication Technologies (ICTs) Servicing Farm Radio: New Contents, New Partnerships. Available at: http://www.fao.org/documents/show_cdr.asp?url_file=/docrep/003/x6721e/x6721 e15.htm (accessed 17 September 2009).

Manyozo, L. (2005), "The practice of participation in broadcasting for development in post-independent Malawi”, Journal of Social Development in Africa. Vol. 20 No. 1, pp. 77-105.

Megwa, E.R. (2007), “Community Radio Stations as Community Technology Centres: An Evaluation of the Development Impact of Technological Hybridization on Stakeholder Communities in South Africa", Journal of Radio Studies, Vol. 14 No. 1, pp. 49-66.

Morton, J. \& Matthewman, R. (1996), "Improving livestock products through extension: information needs institutions and opportunities", Natural Resource Perspective, 12, Overseas Resource Development Institute (ODI), London. 
Nwaerondu, N.G. \& Thompson, G. (1987), "The use of educational radio in developing countries: lessons from the past”, The Journal of Distance Education, Vol. 2 No. 2, pp. 43-54.

Okwu, O.J., Kuku, A.A., \& Aba, J.I. (2007), "An assessment of use of radio in agricultural information dissemination: a case study of radio Benue in Nigeria", African Journal of Agricultural Research, Vol. 2 No. 1, pp. 014-018.

Riesenberg, L. \& Gor, C.O. (1989), "Farmers' preferences for methods of receiving information on new or innovative farming practices", Journal of Agricultural Education, Vol. 30 No. 3, pp 7-13. available at: http://pubs.aged.tamu.edu/jae/pdf/Vol30/30-03-07.pdf (accessed 26 July 2009).

SADC. (2007), "SADC Multi-country agricultural productivity programme (SADCMAPP): National consultative workshop proceedings, 10-11 September 2007, Harare, Zimbabwe", available at: http://www.sadc.int/fanr/agricresearch/mapp/workshops/Zimbabwe\%20workshop \%20report.pdf (accessed 14 December 2009).

Singhal, A. \& Rogers, E. M. (1999), Entertainment-Education: A Communication Strategy for Social Change. New Jersey: Lawrence Erlbaum Associates.

Youdeowei, A., Diallo, A. \& Spiff, E.D. (1996), "Synthesis of regional studies of agricultural information needs of African countries", In The role of information for rural development in ACP countries: review and perspectives. Proceedings of an international seminar, 12-16 Jun 1995, Montpellier, France. Technical Centre for Agricultural and Rural Cooperation, Wageningen, Netherlands. pp. 113-138.

Zijp, W. (1994), Improving the transfer and use of agricultural information: a guide to information technology. Washington DC: World Bank. World Bank Discussion Paper No. 247. 105 pp.

\section{About the authors}

Sailas Nyareza is a Graduate Student in the Department of Information Science, School of Information Technology, University of Pretoria, South Africa. Sailas Nyareza is the 
corresponding author and can be contacted at: sailas.nyareza@gmail.com

Archie L. Dick is a Professor in the Department of Information Science, School of Information Technology, University of Pretoria, South Africa. 